\title{
Use of Proton Pump Inhibitors Is Associated With Anemia in Cardiovascular Outpatients
}

\author{
Toshiyuki Shikata, BSc; Naoko Sasaki, BSc; Masahiro Ueda, BSc; Takeshi Kimura, PhD; \\ Kanako Itohara, MD; Masataka Sugahara, MD; Miho Fukui, MD; Eri Manabe, MD; \\ Tohru Masuyama, MD, PhD; Takeshi Tsujino, MD, PhD
}

\begin{abstract}
Background: Proton pump inhibitors (PPI) are frequently prescribed in combination with aspirin for preventing peptic ulcer in patients with atherosclerotic diseases. In contrast, long-term use of PPI has been suggested to be associated with iron or vitamin $\mathrm{B}_{12}$ deficiency. The effect of PPI on hemoglobin $(\mathrm{Hb})$ concentration, however, has not been clarified in cardiovascular outpatients.
\end{abstract}

\begin{abstract}
Methods and Results: We retrospectively investigated the clinical characteristics of 278 continuous outpatients who received blood test including complete blood count and serum creatinine concentration (mean age, $69.9 \pm 10.8$ years; male, $68.7 \%$ ). The frequency of anemia was $51 \%$ in patients receiving PPI and $19 \%$ in those not receiving PPI (chi-squared test, $P<0.001)$. On multivariate analysis female sex $(P<0.001)$, peripheral artery disease $(P=0.003)$, PPI $(P=0.003)$, low white blood cell count $(P=0.004)$, old age $(P=0.007)$, and low estimated glomerular filtration rate $(P=0.010)$ were independently associated with low $\mathrm{Hb}$. Among these patients, we investigated the change in $\mathrm{Hb}$ after the initiation of $\mathrm{PPI}$ in 36 patients for whom data on $\mathrm{Hb}$ level within 1 year before and within 1 year after the initiation of PPI were available. Mean decrease in $\mathrm{Hb}$ after the initiation of PPI was $0.38 \pm 0.87 \mathrm{~g} / \mathrm{dl}(95 \%$ confidence interval: -0.67 to $-0.09 \mathrm{~g} / \mathrm{dl})$.
\end{abstract}

Conclusions: Use of PPI was associated with anemia in Japanese cardiovascular outpatients. （Circ J 2015; 79: 193-200)

Key Words: Anemia; Cardiovascular disease; Hemoglobin; Proton pump inhibitor

$\mathbf{P}$ roton pump inhibitors (PPI) are one of the most widely used medications worldwide. Although these drugs are considered safe and have been approved for longterm use, some long-term safety concerns have been raised, such as respiratory infection, Clostridium difficile infection, vitamin $\mathrm{B}_{12}$ deficiency, and bone fracture. Iron deficiency anemia is also a concern. ${ }^{1}$ Gastric acid plays an important role in iron absorption because ferric iron is not soluble at high $\mathrm{pH}$. Furthermore, Marcuard et al reported that PPI decreased the absorption rate of vitamin $\mathrm{B}_{12 .}{ }^{2}$

The risk of peptic ulcer complications, particularly bleeding, has been raised in association with aspirin use, and the odds ratio (OR) of bleeding in an epidemiologic study was 2.4. ${ }^{3}$ In that same study, use of PPI was associated with a decrease of $80 \%$ in the risk of upper gastrointestinal bleeding in patients taking low-dose aspirin. Thus, some PPI were indicated for the prevention of gastroduodenal ulcer relapse during aspirin therapy, and guidelines advocate the use of PPI in a wide group of patients with atherosclerosis. ${ }^{4}$ Therefore, PPI are frequently prescribed for cardiovascular outpatients. Furthermore, given that novel anticoagulant drugs have been marketed,,$^{5-7}$ chronic use of PPI might increase in patients with cardiovascular disease. In contrast, cardiovascular outpatients have an increased risk of developing heart failure due to the frequent complications of hypertension or ischemic heart disease. Anemia is a factor indicating poor outcome in both patients with heart failure with a reduced ejection fraction and heart failure with a preserved ejection fraction. ${ }^{8-10}$ Moreover, anemia has been shown to predict mortality in patients undergoing their first coronary revascularization. ${ }^{11}$ Therefore, appropriate care should be taken if PPI cause anemia in cardiovascular outpatients.

This retrospective study was thus designed to determine how PPI influence blood hemoglobin $(\mathrm{Hb})$ level in cardiovascular outpatients.

Received May 22, 2014; accepted October 2, 2014; released online November 12, 2014 Time for primary review: 27 days

Department of Pharmacy, Hyogo College of Medicine Hospital, Nishinomiya (T.S., M.U., T.K.); Graduate School of Pharmacy (T.S., T.T.), Department of Pharmacy, School of Pharmacy (N.S., T.T.), Hyogo University of Health Sciences, Kobe; and Cardiovascular Division, Department of Internal Medicine, Hyogo College of Medicine, Nishinomiya (K.I., M.S., M.F., E.M., T.M., T.T.), Japan

Mailing address: Takeshi Tsujino, MD, PhD, Department of Pharmacy, School of Pharmacy, Hyogo University of Health Sciences, 1-3-6 Minatojima, Chuo-ku, Kobe 650-8530, Japan. E-mail: ttsujino@huhs.ac.jp

ISSN-1346-9843 doi:10.1253/circj.CJ-14-0582

All rights are reserved to the Japanese Circulation Society. For permissions, please e-mail: cj@j-circ.or.jp 


\begin{tabular}{|c|c|c|c|c|c|}
\hline Clinical characteristics & All & $\begin{array}{c}\text { No acid } \\
\text { suppression agent }\end{array}$ & $\begin{array}{l}\text { Patients with } \\
\mathrm{H}_{2} \text {-blocker }\end{array}$ & $\begin{array}{l}\text { Patients } \\
\text { with PPI }\end{array}$ & P-value \\
\hline$n$ & 278 & 166 & 24 & 88 & \\
\hline Age (years) & $69.9 \pm 10.8$ & $68.4 \pm 11.5$ & $73.4 \pm 8.4$ & $71.8 \pm 9.6^{*}$ & 0.015 \\
\hline Male gender & $191(68.7)$ & $115(69.3)$ & $18(75.0)$ & $58(65.9)$ & 0.675 \\
\hline BMI $\left(\mathrm{kg} / \mathrm{m}^{2}\right)$ & $23.8 \pm 3.9$ & $24.1 \pm 4.1$ & $22.9 \pm 3.0$ & $23.5 \pm 3.7$ & 0.251 \\
\hline $\mathrm{SBP}(\mathrm{mmHg})$ & $131.4 \pm 20.1$ & $133.5 \pm 19.8$ & $129.7 \pm 20.1$ & $127.9 \pm 20.4$ & 0.130 \\
\hline $\mathrm{DBP}(\mathrm{mmHg})$ & $76.0 \pm 12.8$ & $77.2 \pm 13.6$ & $72.6 \pm 10.0$ & $74.6 \pm 11.6$ & 0.155 \\
\hline Heart rate (beats/min) & $73.9 \pm 13.2$ & $75.1 \pm 13.7$ & $70.8 \pm 11.2$ & $72.2 \pm 12.6$ & 0.237 \\
\hline $\operatorname{RBC}\left(10^{4} / \mu \mathrm{l}\right)$ & $443.7 \pm 58.4$ & $454.3 \pm 57.5$ & $445.3 \pm 43.4$ & $423.4 \pm 58.6^{\star \star}$ & $<0.001$ \\
\hline $\mathrm{Hb}(\mathrm{g} / \mathrm{dl})$ & $13.6 \pm 1.8$ & $14.0 \pm 1.7$ & $13.4 \pm 1.5$ & $12.8 \pm 1.8^{\star \star}$ & $<0.001$ \\
\hline $\mathrm{Ht}(\%)$ & $41.0 \pm 5.1$ & $42.2 \pm 4.9$ & $40.7 \pm 4.2$ & $38.9 \pm 5.2^{* *}$ & $<0.001$ \\
\hline $\operatorname{MCV}(\mathrm{fl})$ & $92.6 \pm 5.3$ & $93.0 \pm 5.1$ & $91.5 \pm 5.1$ & $92.1 \pm 5.7$ & 0.233 \\
\hline $\mathrm{MCH}(\mathrm{pg})$ & $30.6 \pm 1.9$ & $30.9 \pm 1.7$ & $30.2 \pm 2.1$ & $30.2 \pm 2.3^{*}$ & 0.011 \\
\hline $\mathrm{MCHC}(\mathrm{g} / \mathrm{dl})$ & $33.1 \pm 1.0$ & $33.2 \pm 1.0$ & $33.0 \pm 1.0$ & $32.8 \pm 1.1^{\star *}$ & 0.003 \\
\hline WBC $\left(10^{2} / \mu \mathrm{l}\right)$ & $60.3 \pm 17.1$ & $60.8 \pm 17.5$ & $61.9 \pm 13.7$ & $59.1 \pm 17.2$ & 0.685 \\
\hline Plt $\left(10^{4} / \mu \mathrm{l}\right)$ & $19.3 \pm 5.5$ & $19.3 \pm 5.7$ & $19.9 \pm 3.8$ & $18.9 \pm 5.3$ & 0.712 \\
\hline eGFR $\left(\mathrm{ml} \cdot \mathrm{min}^{-1} \cdot 1.73 \mathrm{~m}^{-2}\right)$ & $65.8 \pm 21.2$ & $69.2 \pm 20.5$ & $64.3 \pm 15.6$ & $59.8 \pm 22.7^{\star \star}$ & 0.003 \\
\hline $\mathrm{UA}(\mathrm{mg} / \mathrm{dl})$ & $5.8 \pm 1.6$ & $5.8 \pm 1.4$ & $5.6 \pm 1.5$ & $6.0 \pm 1.8$ & 0.448 \\
\hline $\mathrm{Na}(\mathrm{mEq} / \mathrm{L})$ & $139.9 \pm 2.7$ & $140.2 \pm 2.0$ & $139.7 \pm 1.9$ & $139.4 \pm 3.7$ & 0.093 \\
\hline $\mathrm{K}(\mathrm{mEq} / \mathrm{L})$ & $4.3 \pm 0.4$ & $4.3 \pm 0.4$ & $4.2 \pm 0.4$ & $4.3 \pm 0.4$ & 0.308 \\
\hline $\mathrm{Cl}(\mathrm{mEq} / \mathrm{L})$ & $104.3 \pm 2.9$ & $104.4 \pm 2.4$ & $103.9 \pm 2.5$ & $104.2 \pm 3.7$ & 0.668 \\
\hline \multicolumn{6}{|l|}{ Comorbidity } \\
\hline History of gastroduodenal ulcer ${ }^{\dagger}$ & $21(7.6)$ & $11(6.6)$ & $3(12.5)$ & $7(8.0)$ & 0.587 \\
\hline Reflux esophagitis $^{\dagger}$ & $25(9.0)$ & $10(6.0)$ & $1(4.2)$ & $14(15.9)^{\star}$ & 0.022 \\
\hline Hypertension & $193(69.4)$ & $115(69.3)$ & $14(58.3)$ & $64(72.7)$ & 0.398 \\
\hline Diabetes mellitus & $104(37.4)$ & $58(34.9)$ & $13(54.2)$ & $33(37.5)$ & 0.191 \\
\hline Dyslipidemia & $160(57.6)$ & $95(57.2)$ & $12(50.0)$ & $53(60.2)$ & 0.662 \\
\hline Heart failure & $59(21.2)$ & $28(16.9)$ & $4(16.7)$ & $27(30.7)^{\star}$ & 0.032 \\
\hline Angina pectoris & $81(29.1)$ & $43(25.9)$ & 8 (33.3) & $30(34.1)$ & 0.352 \\
\hline Old MI & $81(29.1)$ & $34(20.5)$ & $9(37.5)$ & $38(43.2)^{\star \star}$ & $<0.001$ \\
\hline History of $\mathrm{PCl}$ & $78(28.1)$ & $34(20.5)$ & 8 (33.3) & $36(40.9)^{\star \star}$ & $<0.001$ \\
\hline Cerebral infarction & $27(9.7)$ & $13(7.8)$ & $3(12.5)$ & $11(12.5)$ & 0.436 \\
\hline Cerebral hemorrhage & $5(1.8)$ & $1(0.6)$ & $1(4.2)$ & $3(3.4)$ & 0.183 \\
\hline Dementia & $3(1.1)$ & $2(1.2)$ & - & $1(1.1)$ & 0.980 \\
\hline PAD & $22(7.9)$ & $8(4.8)$ & $2(8.3)$ & $12(13.6)$ & 0.046 \\
\hline \multicolumn{6}{|l|}{ Medication } \\
\hline Statins & $126(45.3)$ & $67(40.4)$ & $8(33.3)$ & $51(58.0)^{*}$ & 0.013 \\
\hline Uric acid-lowering agents & $38(13.7)$ & $25(15.1)$ & $1(4.2)$ & $12(13.6)$ & 0.348 \\
\hline Oral hypoglycemic agents & $59(21.2)$ & $30(18.1)$ & $10(41.7)^{\star}$ & $19(21.6)$ & 0.030 \\
\hline Insulin & $7(2.5)$ & $4(2.4)$ & - & $3(3.4)$ & 0.818 \\
\hline ARB & $148(53.2)$ & $81(48.8)$ & $10(41.7)$ & $57(64.8)$ & 0.026 \\
\hline Diuretics & $83(29.9)$ & $39(23.5)$ & $7(29.2)$ & $37(42.0)^{* *}$ & 0.009 \\
\hline ACEI & $41(14.7)$ & $29(17.5)$ & $2(8.3)$ & $10(11.4)$ & 0.277 \\
\hline Calcium channel blockers & $120(43.2)$ & $72(43.4)$ & $13(54.2)$ & $35(39.8)$ & 0.449 \\
\hline$\beta$-blockers & $134(48.2)$ & $66(39.8)$ & $15(62.5)$ & $53(60.2)^{\star \star}$ & 0.003 \\
\hline Other antihypertensive agents & $16(5.8)$ & $12(7.2)$ & - & $4(4.5)$ & 0.490 \\
\hline Antiplatelet agents & $146(52.5)$ & $69(41.6)$ & $14(58.3)$ & $63(71.6)^{\star \star}$ & $<0.001$ \\
\hline Aspirin & $130(46.8)$ & $58(34.9)$ & $13(54.2)$ & $59(67.0)^{* \star}$ & $<0.001$ \\
\hline DPI & $51(18.3)$ & $19(11.4)$ & $6(25.0)$ & $26(29.5)^{\star \star}$ & 0.001 \\
\hline Warfarin & $61(21.9)$ & $28(16.9)$ & $4(16.7)$ & $29(33.0)^{*}$ & 0.010 \\
\hline Warfarin+DPI & $9(3.2)$ & $3(1.8)$ & $2(8.3)$ & $4(4.5)$ & 0.169 \\
\hline
\end{tabular}

Data given as mean \pm SD or $n(\%)$. Differences in continuous and categorical variables among 3 groups were assessed using 1-way ANOVA and chi-squared test, respectively. ${ }^{*} \mathrm{P}<0.05,{ }^{*} \mathrm{P}<0.01$ compared with no acid suppression agent (1-way ANOVA followed by Tukey post-hoc test or chi-squared test followed by Bonferroni correction). 'Diagnosed on gastrointestinal fiberscopy. ACEI, angiotensin-converting enzyme inhibitor; ARB, angiotensin receptor blocker; BMI, body mass index; DBP, diastolic blood pressure; DPI, dual platelet inhibitor; eGFR, estimated glomerular filtration rate; $\mathrm{H}_{2}$-blocker, histamine type 2 receptor blocker; $\mathrm{Hb}$, hemoglobin; $\mathrm{Ht}$, hematocrit; $\mathrm{MCH}$, mean corpuscular hemoglobin; MCHC, mean corpuscular hemoglobin concentration; MCV, mean corpuscular volume; MI, myocardial infarction; PAD, peripheral artery disease; PCl, percutaneous coronary intervention; Plt, platelet; PPI, proton pump inhibitor; RBC, red blood cells; SBP, systolic blood pressure; statins, HMG-CoA reductase inhibitor; UA, uric acid; WBC, white blood cells. 


\section{Methods}

\section{Subjects}

We retrospectively investigated continuous outpatients who visited the Cardiovascular Division, Department of Internal Medicine, Hyogo College of Medicine Hospital from February 2011 to October 2012 for the treatment of cardiovascular disease (ischemic heart disease, heart failure, peripheral artery disease, cerebrovascular disease, cardiomyopathy, and arrhythmia) or risk factors of cardiovascular disease (hypertension, dyslipidemia, diabetes mellitus, and hyperuricemia), and who underwent complete blood count (CBC) and measurement of serum creatinine. We reviewed patient demographics, comorbidity, and medication in their medical records. Exclusion criteria were as follows: history of digestive system surgery, malignancy, hemodialysis, aplastic anemia, hemolytic anemia, major bleeding within 1 year, inflammatory disease, connective tissue disease, and use of erythropoietin, vitamins, iron or folic acid preparations. A Japanese equation was used to calculate estimated glomerular filtration rate (eGFR): eGFR (ml . $\left.\mathrm{min}^{-1} \cdot 1.73 \mathrm{~m}^{-2}\right)=194 \times$ serum creatinine ${ }^{-1.094} \times \mathrm{age}^{-0.287}(\times 0.739$ if female). ${ }^{12}$ Diabetes mellitus was defined as fasting plasma glucose $\geq 126 \mathrm{mg} / \mathrm{dl}$, HbA1c $\geq 6.5 \%$, or use of anti-diabetic medication. Hypertension was defined as systolic blood pressure (SBP) $\geq 140 \mathrm{mmHg}$, diastolic blood pressure (DBP) $\geq 90 \mathrm{mmHg}$, or use of anti-hypertensive medication. Dyslipidemia was defined as low-density lipoprotein cholesterol $\geq 140 \mathrm{mg} / \mathrm{dl}$, high-density lipoprotein cholesterol $<40 \mathrm{mg} / \mathrm{dl}$, triglyceride $\geq 150 \mathrm{mg} / \mathrm{dl}$, or use of anti-dyslipidemia medication. Anemia was defined according to the World Health Organization criteria $(\mathrm{Hb}<13 \mathrm{~g} / \mathrm{dl}$ in men, $<12 \mathrm{~g} / \mathrm{dl}$ in women).

Next, we examined the change in $\mathrm{Hb}$ level after the initiation of PPI in patients who did not have heart failure and whose medication was not changed except for the initiation of PPI between the CBC before and after the initiation of PPI. They underwent $\mathrm{CBC}$ at least once within 1 year before, and again within 1 year after the initiation of PPI. To calculate the change in $\mathrm{Hb}$ after the initiation of PPI, the average Hb level within 1 year after the initiation of PPI was subtracted from that within 1 year before the initiation of PPI.

This study was approved by the Ethics Committee of Hyogo College of Medicine and the Ethics Committee of Hyogo University of Health Sciences.

\section{Statistical Analysis}

Data are given as mean \pm SD. Differences in categorical variables between groups were assessed using chi-squared test. Differences in continuous variables between groups were assessed using unpaired Student's t-test or 1-way analysis of variance (ANOVA) followed by Tukey post-hoc test. Regarding continuous variables, the correlation between each variable was examined using Pearson's correlation analysis. Multiple regression analysis and logistic regression analysis were used to identify variables that might predict $\mathrm{Hb}$ level and anemia, respectively. Factors with $\mathrm{P}<0.10$ on univariate analysis were selected as independent factors in multivariate analysis. Hb level before and after the initiation of PPI was compared using paired t-test. Differences were considered statistically significant for $\mathrm{P}<0.05$. All calculations and analyses were performed using Ekuseru-Toukei 2010 (Social Survey Research Information).

\begin{tabular}{|c|c|c|}
\hline Factor & $\mathbf{R}$ & P-value \\
\hline Age & -0.361 & $<0.001$ \\
\hline BMI & 0.210 & 0.001 \\
\hline SBP & 0.084 & 0.194 \\
\hline DBP & 0.207 & 0.001 \\
\hline Heart rate & -0.125 & 0.078 \\
\hline WBC & 0.169 & 0.005 \\
\hline Plt & 0.054 & 0.372 \\
\hline eGFR & 0.337 & $<0.001$ \\
\hline UA & -0.033 & 0.633 \\
\hline $\mathrm{Na}$ & 0.141 & 0.023 \\
\hline K & -0.079 & 0.207 \\
\hline $\mathrm{Cl}$ & -0.083 & 0.184 \\
\hline
\end{tabular}

Pearson's correlation analysis. Abbreviations as in Table 1.

\section{Results}

\section{Univariate Factors Associated With $\mathrm{Hb}$}

We screened 634 patients, and 278 patients were enrolled. Table 1 lists the clinical characteristics, comorbidities, and medications. The reasons for PPI prescription were as follows: reflux esophagitis $(n=85)$, use of antiplatelet agents $(n=63)$, history of gastroduodenal ulcer $(n=30)$, and use of warfarin $(n=7)$. When reflux esophagitis and gastroduodenal ulcer were diagnosed on gastrointestinal fiberscopy, they were analyzed as factors for $\mathrm{Hb}$ concentration and anemia. PPI users tended to be older, had worse renal function, and had a higher rate of treatment with diuretics, antiplatelet agents or warfarin, and had a higher prevalence of comorbidities (Table 1). Among them, there were 36 patients who underwent $\mathrm{CBC}$ at least once within 1 year before, and again within 1 year after the initiation of PPI.

On Pearson's correlation analysis the following continuous variables correlated significantly with $\mathrm{Hb}$ level: age, body mass index (BMI), DBP, white blood cell (WBC), eGFR, and serum $\mathrm{Na}$ concentration (Table 2). Among categorical variables, the following were associated with $\mathrm{Hb}$ on unpaired Student's ttest: gender, heart failure, peripheral artery disease, and use of PPI, diuretics, or antiplatelet agents (Table 3).

\section{Multivariate Factors Associated With Hb}

Multiple regression analysis was performed to examine the factors associated with $\mathrm{Hb}$ level, using the following factors with $\mathrm{P}<0.1$ on univariate analysis: age, gender, $\mathrm{BMI}$, DBP, WBC, eGFR, Na, heart rate, heart failure, peripheral artery disease, and use of PPI, diuretics, and antiplatelet agents. Female sex, peripheral artery disease, use of PPI, low WBC, old age, and low eGFR were independently associated with low $\mathrm{Hb}$ (Table 4).

\section{Factors Associated With Anemia}

Table 5 lists differences of clinical characteristics between patients with anemia and those without anemia. Among continuous variables, the following were significantly different between patients with and those without anemia on unpaired Student's t-test: age, BMI, SBP, DBP, WBC, platelet, eGFR, uric acid, and serum $\mathrm{Na}$ and $\mathrm{K}$ concentration. Among categorical variables, the following factors were significantly different between patients with anemia and those without anemia on chi-squared test: gender, history of gastroduodenal ulcer, heart 
Table 3. Effects of Medication and Comorbidity on $\mathrm{Hb}$ Concentration

Clinical characteristics

Male (+)/Female (-)

Comorbidity

History of gastroduodenal ulcer

Reflux esophagitis

Hypertension

Diabetes mellitus

Dyslipidemia

Heart failure

Angina pectoris

Old MI

History of $\mathrm{PCl}$

Cerebral infarction

Cerebral hemorrhage

Dementia

PAD

Medication

Proton pump inhibitor

$\mathrm{H}_{2}$-blockers

Statins

Uric acid-lowering agent

Oral hypoglycemic agent

Insulin

ARB

Diuretics

ACEI

Calcium channel blocker

$\beta$-blocker

Other anti-hypertensive agent

Antiplatelet agent

Aspirin

DPI

Warfarin

Warfarin+DPI
Hemoglobin $(g / d l)$

$$
\text { (+) }
$$

$14.1 \pm 1.7$

$13.9 \pm 1.3$

$13.4 \pm 1.9$

$13.6 \pm 1.9$

$13.4 \pm 1.8$

$13.5 \pm 1.7$

$13.1 \pm 2.1$

$13.5 \pm 1.8$

$13.6 \pm 1.9$

$13.8 \pm 1.8$

$13.2 \pm 1.9$

$12.9 \pm 2.5$

$12.2 \pm 1.5$

$12.2 \pm 2.0$

$12.8 \pm 1.8$

$13.4 \pm 1.5$

$13.7 \pm 1.8$

$14.0 \pm 2.0$

$13.4 \pm 1.7$

$12.8 \pm 1.8$

$13.5 \pm 1.9$

$13.0 \pm 2.0$

$13.9 \pm 2.1$

$13.6 \pm 1.8$

$13.6 \pm 2.0$

$13.3 \pm 2.1$

$13.3 \pm 1.8$

$13.4 \pm 1.8$

$13.3 \pm 2.0$

$13.5 \pm 2.0$

$13.6 \pm 2.0$

(-)

$12.5 \pm 1.6$

$13.5 \pm 1.9$

$13.6 \pm 1.8$

$13.6 \pm 1.9$

$13.7 \pm 1.8$

$13.6 \pm 2.0$

$13.7 \pm 1.8$

$13.6 \pm 1.9$

$13.5 \pm 1.8$

$13.5 \pm 1.9$

$13.6 \pm 1.8$

$13.6 \pm 1.8$

$13.6 \pm 1.8$

$13.7 \pm 1.8$

$13.9 \pm 1.7$

$13.6 \pm 1.9$

$13.5 \pm 1.9$

$13.5 \pm 1.8$

$13.6 \pm 1.9$

$13.6 \pm 1.8$

$13.6 \pm 1.8$

$13.8 \pm 1.7$

$13.5 \pm 1.8$

$13.5 \pm 1.9$

$13.5 \pm 1.7$

$13.6 \pm 1.8$

$13.8 \pm 1.8$

$13.7 \pm 1.8$

$13.6 \pm 1.8$

$13.6 \pm 1.8$

$13.6 \pm 1.8$
P-value

$<0.001$

0.452

0.559

0.968

0.234

0.878

0.022

0.798

0.631

0.143

0.303

0.418

0.187

$<0.001$

$<0.001$

0.696

0.408

0.132

0.482

0.277

0.799

$<0.001$

0.251

0.879

0.757

0.559

0.039

0.199

0.194

0.909

0.993

Data given as mean \pm SD. Differences in continuous variables between groups were assessed using unpaired Student's t-test. Abbreviations as in Table 1.

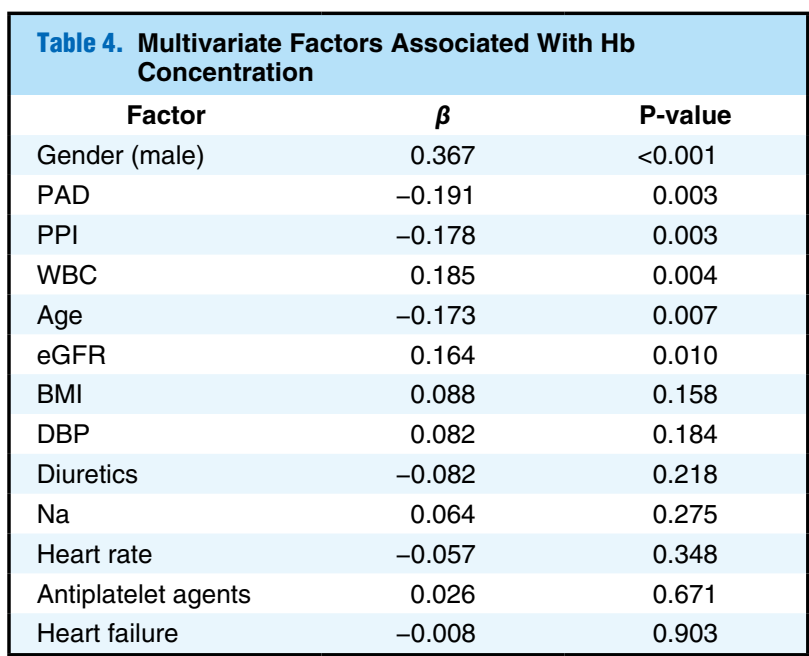

Abbreviations as in Table 1. failure, peripheral artery disease, and use of PPI, diuretics, $\beta$-blockers, antiplatelet agents, aspirin, or dual platelet inhibitors (DPI).

In order to examine the factors associated with anemia, logistic regression analysis was performed using the following factors with $\mathrm{P}<0.1$ on univariate analysis: age, gender, BMI, SBP, DBP, WBC, platelet, eGFR, uric acid, serum $\mathrm{Na}$ and $\mathrm{K}$ concentration, history of gastroduodenal ulcer, diabetes mellitus, heart failure, peripheral artery disease, and use of PPI, oral hypoglycemic agents, $\beta$-blockers, and antiplatelet agents. Use of aspirin and DPI were excluded because it is a confounding factor for the antiplatelet agent. Similarly, use of diuretics was excluded because it is a confounding factor for heart failure. Use of PPI, low eGFR, old age, and low WBC were independently associated with anemia (Table 6).

\section{Acid Suppression Agents and Incidence of Anemia}

The frequency of anemia according to WHO criteria was $51 \%$ in patients receiving PPI $(\mathrm{n}=88)$, and $19 \%$ in those not receiving PPI ( $n=190$; chi-squared test, $\mathrm{P}<0.001)$. In patients who 


\begin{tabular}{|c|c|c|c|}
\hline Clinical characteristics & With anemia & Without anemia & P-value \\
\hline $\mathrm{n}$ & 81 & 197 & \\
\hline Age (years) & $75.4 \pm 9.7$ & $67.7 \pm 10.4$ & $<0.001$ \\
\hline Male gender & $50(61.7)$ & $141(71.6)$ & 0.019 \\
\hline $\mathrm{BMI}\left(\mathrm{kg} / \mathrm{m}^{2}\right)$ & $23.1 \pm 4.0$ & $24.2 \pm 3.9$ & 0.038 \\
\hline $\mathrm{SBP}(\mathrm{mmHg})$ & $127.0 \pm 21.5$ & $133.3 \pm 19.3$ & 0.026 \\
\hline $\mathrm{DBP}(\mathrm{mmHg})$ & $71.8 \pm 12.0$ & $77.8 \pm 12.7$ & $<0.001$ \\
\hline Heart rate (beats/min) & $75.7 \pm 14.6$ & $73.2 \pm 12.6$ & 0.237 \\
\hline $\mathrm{Hb}(\mathrm{g} / \mathrm{dl})$ & $11.4 \pm 1.1$ & $14.4 \pm 1.2$ & $<0.001$ \\
\hline WBC $\left(10^{2} / \mu \mathrm{l}\right)$ & $56.4 \pm 17.0$ & $61.9 \pm 16.9$ & 0.015 \\
\hline PIt $\left(10^{4} / \mu \mathrm{l}\right)$ & $18.0 \pm 5.4$ & $19.8 \pm 5.4$ & 0.013 \\
\hline eGFR $\left(\mathrm{ml} \cdot \mathrm{min}^{-1} \cdot 1.73 \mathrm{~m}^{-2}\right)$ & $52.1 \pm 20.3$ & $71.5 \pm 19.0$ & $<0.001$ \\
\hline UA (mg/dL) & $6.2 \pm 2.0$ & $5.7 \pm 1.3$ & 0.040 \\
\hline $\mathrm{Na}(\mathrm{mEq} / \mathrm{L})$ & $139.0 \pm 3.9$ & $140.2 \pm 1.8$ & $<0.001$ \\
\hline $\mathrm{K}(\mathrm{mEq} / \mathrm{L})$ & $4.4 \pm 0.4$ & $4.3 \pm 0.3$ & 0.022 \\
\hline $\mathrm{Cl}(\mathrm{mEq} / \mathrm{L})$ & $104.3 \pm 3.9$ & $104.3 \pm 2.3$ & 0.921 \\
\hline \multicolumn{4}{|l|}{ Comorbidity } \\
\hline History of gastroduodenal ulcer & $2(2.5)$ & $19(9.6)$ & 0.045 \\
\hline Reflux esophagitis & $10(12.3)$ & $15(7.6)$ & 0.249 \\
\hline Hypertension & $59(72.8)$ & $134(68.0)$ & 0.476 \\
\hline Diabetes mellitus & $37(45.7)$ & $67(34.0)$ & 0.077 \\
\hline Dyslipidemia & $43(53.1)$ & $117(59.4)$ & 0.352 \\
\hline Heart failure & $29(35.8)$ & $30(15.2)$ & $<0.001$ \\
\hline Angina pectoris & 27 (33.3) & $54(27.4)$ & 0.384 \\
\hline Old MI & $29(35.8)$ & $52(26.4)$ & 0.146 \\
\hline History of $\mathrm{PCl}$ & $23(28.4)$ & $55(27.9)$ & 1.000 \\
\hline Cerebral infarction & $11(13.6)$ & $16(8.1)$ & 0.183 \\
\hline Cerebral hemorrhage & $3(3.7)$ & $2(1.0)$ & 0.150 \\
\hline Dementia & $2(2.5)$ & $1(0.5)$ & 0.204 \\
\hline PAD & $14(17.3)$ & $8(4.1)$ & $<0.001$ \\
\hline \multicolumn{4}{|l|}{ Medication } \\
\hline Proton pump inhibitor & $45(55.6)$ & $43(21.8)$ & $<0.001$ \\
\hline $\mathrm{H}_{2}$-blocker & $8(9.9)$ & $16(8.1)$ & 0.643 \\
\hline Statins & $35(43.2)$ & $91(46.2)$ & 0.692 \\
\hline Uric acid-lowering agent & $14(17.3)$ & $24(12.2)$ & 0.256 \\
\hline Oral hypoglycemic agent & $23(28.4)$ & $36(18.3)$ & 0.076 \\
\hline Insulin & $4(4.9)$ & $3(1.5)$ & 0.199 \\
\hline ARB & $44(54.3)$ & $104(52.8)$ & 0.895 \\
\hline Diuretics & $42(51.9)$ & $41(20.8)$ & $<0.001$ \\
\hline ACEI & $14(17.3)$ & $27(13.7)$ & 0.460 \\
\hline Calcium channel blocker & $39(48.1)$ & $81(41.1)$ & 0.290 \\
\hline$\beta$-blockers & $50(61.7)$ & $84(42.6)$ & 0.005 \\
\hline Other antihypertensive agent & $6(7.4)$ & $10(5.1)$ & 0.571 \\
\hline Antiplatelet agent & $55(67.9)$ & $91(46.2)$ & 0.001 \\
\hline Aspirin & $48(59.3)$ & $82(41.6)$ & 0.008 \\
\hline DPI & $21(25.9)$ & $30(15.2)$ & 0.042 \\
\hline Warfarin & $22(27.2)$ & $39(19.8)$ & 0.203 \\
\hline Warfarin+DPI & $3(3.7)$ & $6(3.0)$ & 0.723 \\
\hline
\end{tabular}

Data given as mean \pm SD or $\mathrm{n}(\%)$. Differences in continuous and categorical variables between groups were assessed using unpaired Student's t-test and chi-squared test, respectively. Abbreviations as in Table 1.

did not receive PPI, the frequency of anemia was $17 \%$ in patients not taking acid suppression agents $(n=166)$, whereas it was $33 \%$ in patients taking histamine $\mathrm{H}_{2}$-receptor blocker $(n=24)$. The differences in frequency of anemia among the 3 groups were statistically significant only between patients who received PPI and those who received no acid suppression agents (chi-squared test followed by Bonferroni correction, $\mathrm{P}<0.001)$. Figure shows the effect of acid suppression agents on $\mathrm{Hb}$ and mean corpuscular volume (MCV). Mean $\mathrm{Hb}$ was $12.8 \pm 1.8 \mathrm{~g} / \mathrm{dl}$ in patients with PPI, $13.4 \pm 1.5 \mathrm{~g} / \mathrm{dl}$ in patients with $\mathrm{H}_{2}$-blocker, and $14.0 \pm 1.7 \mathrm{~g} / \mathrm{dl}$ in patients with no acid suppression agents $(\mathrm{P}<0.001$, PPI vs. no acid suppression 


\begin{tabular}{lcc|}
$\begin{array}{l}\text { Table 6. } \begin{array}{l}\text { Logistic Regression: Factors Associated With } \\
\text { Anemia }\end{array} \\
\text { Factor }\end{array}$ & $\boldsymbol{\beta}$ & P-value \\
PPI & 0.893 & $<0.001$ \\
eGFR & -1.078 & 0.005 \\
Age & 0.737 & 0.025 \\
WBC & -0.733 & 0.031 \\
PAD & 0.507 & 0.082 \\
Antiplatelet agents & -0.446 & 0.168 \\
Na & -0.365 & 0.185 \\
Plt & 0.309 & 0.269 \\
UA & -0.327 & 0.317 \\
Diabetes mellitus & 0.372 & 0.323 \\
$\beta$-blocker & 0.275 & 0.352 \\
Heart failure & 0.249 & 0.361 \\
DBP & -0.303 & 0.384 \\
K & -0.196 & 0.493 \\
Gender (male) & -0.172 & 0.506 \\
Oral hypoglycemic agents & 0.169 & 0.640 \\
SBP & -0.073 & 0.839 \\
BMI & 0.040 & 0.888 \\
History of gastroduodenal ulcer & -0.013 & 0.990 \\
\hline Abbrevation as in Table 1 & &
\end{tabular}

Abbreviations as in Table 1.

agents; 1-way ANOVA followed by Tukey post-hoc test), whereas MCV was not significantly different between the 3 groups.

\section{Decrease in Hb After Initiation of PPI}

Among 278 patients, we examined the change in $\mathrm{Hb}$ after the initiation of PPI in 36 patients who underwent $\mathrm{CBC}$ at least once within 1 year before and again 1 year after the initiation of PPI. We compared average Hb level within 1 year before initiation of PPI and that within 1 year after the initiation of PPI. $\mathrm{Hb}$, mean corpuscular $\mathrm{Hb}$ concentration, platelets and red blood cells significantly decreased after the initiation of PPI (Table 7). Decrease in average $\mathrm{Hb}$ was $0.38 \pm 0.87 \mathrm{~g} / \mathrm{dl}(95 \%$ confidence interval: -0.67 to $-0.09 \mathrm{~g} / \mathrm{dl}$ ). Serum creatinine increased after initiation of PPI, but the change in $\mathrm{Hb}$ was not correlated with the change in creatinine $(\mathrm{r}=-0.13, \mathrm{P}=0.44)$.

\section{Discussion}

In order to verify the association between PPI and anemia, we retrospectively investigated the clinical characteristics of 278 continuous outpatients who visited the Cardiovascular Division of Hyogo College of Medicine Hospital. The frequency of anemia was significantly higher in patients receiving PPI than in those receiving no PPI. Multivariate analysis confirmed that PPI treatment was independently associated with low $\mathrm{Hb}$ and anemia. Moreover, decrease in average $\mathrm{Hb}$ during 1 year after PPI treatment was $0.38 \pm 0.87 \mathrm{~g} / \mathrm{dl}$, which was significantly greater than the reported annual decrease in $\mathrm{Hb}$ of $0.08-0.04 \mathrm{~g} / \mathrm{dl} /$ year for men and $0.05-0.04 \mathrm{~g} / \mathrm{dl} / \mathrm{year}$ for women. ${ }^{13}$ These findings suggest that PPI decrease $\mathrm{Hb}$. It is possible that PPI were prescribed to the patients with peptic ulcer and that the peptic ulcer itself caused anemia, but patients with major bleeding within 1 year were excluded from the present study and history of peptic ulcer was not associated with low $\mathrm{Hb}$ in the present subjects. Thus, we think that PPI treatment, not gastrointestinal bleeding, caused anemia. The present findings suggest that PPI use is one of the causes of cryptogenic anemia in cardiovascular outpatients. PPI should be continued, however, in most patients who take antiplatelet agents or anticoagulants. First, PPI have been clearly demonstrated to prevent gastrointestinal bleeding among pa-
A

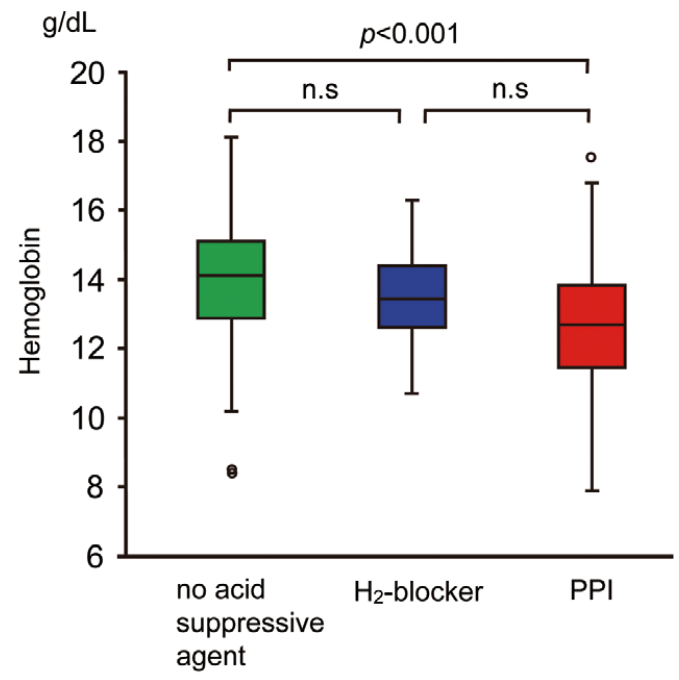

B

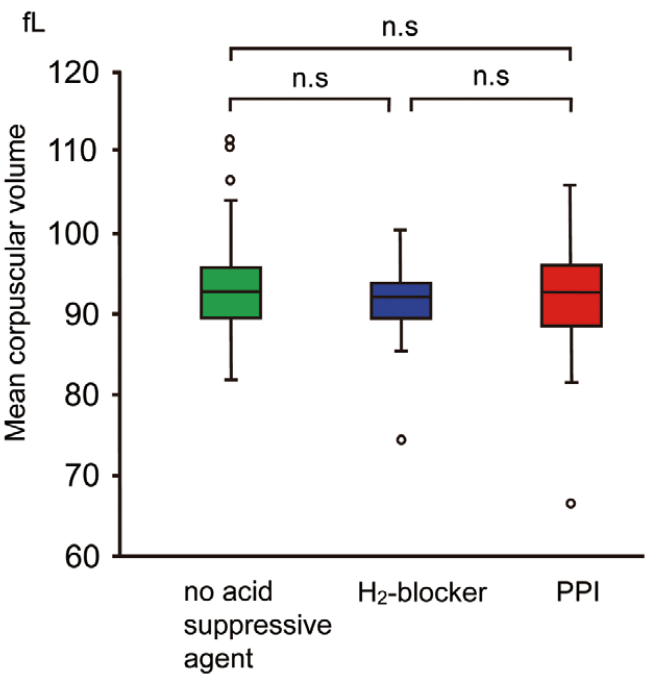

Figure. Box plot of (A) hemoglobin and (B) mean corpuscular volume vs. acid suppression agent. Box, interquartile range; horizontal line within box, median; whiskers, smallest and largest non-outlier values; open circles, outliers. PPI, proton pump inhibitor. 


\begin{tabular}{|c|c|c|c|}
\hline & $\begin{array}{c}\text { Before initiation } \\
\text { of PPI }\end{array}$ & $\begin{array}{l}\text { After initiation } \\
\text { of PPI }\end{array}$ & P-value \\
\hline $\mathrm{Hb}(\mathrm{g} / \mathrm{dl})$ & $13.5 \pm 1.9$ & $13.1 \pm 1.9$ & 0.013 \\
\hline $\mathrm{MCH}(\mathrm{pg})$ & $30.7 \pm 1.7$ & $30.6 \pm 1.7$ & 0.311 \\
\hline $\mathrm{MCHC}(\mathrm{g} / \mathrm{dl})$ & $33.1 \pm 0.9$ & $32.9 \pm 0.9$ & 0.017 \\
\hline MCV (fl) & $92.9 \pm 4.0$ & $92.9 \pm 3.9$ & 0.863 \\
\hline Plt $\left(10^{4} / \mu \mathrm{l}\right)$ & $19.7 \pm 3.4$ & $18.8 \pm 3.1$ & 0.014 \\
\hline $\operatorname{RBC}\left(10^{4} / \mu \mathrm{l}\right)$ & $439.6 \pm 54.9$ & $429.4 \pm 51.9$ & 0.048 \\
\hline WBC $\left(10^{2} / \mu \mathrm{l}\right)$ & $65.3 \pm 20.0$ & $62.2 \pm 17.2$ & 0.216 \\
\hline $\mathrm{Cr}(\mathrm{mg} / \mathrm{dl})$ & $0.86 \pm 0.26$ & $0.95 \pm 0.32$ & $<0.001$ \\
\hline
\end{tabular}

Data given as mean $\pm \mathrm{SD}$. $\mathrm{Hb}$ before and after the initiation of PPI was compared using paired t-test. $\mathrm{Cr}$, creatinine.

Other abbreviations as in Table 1.

tients receiving antiplatelet agents and anticoagulants. ${ }^{14,15}$ The COGENT study showed that omeprazole inhibited gastrointestinal events among patients receiving aspirin and clopidogrel in coronary artery disease. ${ }^{16}$ Second, Chitose et al confirmed that PPI were safe to use for cardiovascular events using P2Y12 receptor antagonists in Japanese patients. ${ }^{17}$ In their study, a total of 1,270 patients taking dual antiplatelet therapy, aspirin and thienopyridine, were enrolled and divided into 2 groups according to use of PPI. They concluded that intake of PPI was not associated with an increased risk for adverse clinical outcome in patients treated with stent placement. In the present subjects, the prevalence of history of gastroduodenal ulcer was similar in patients with and those without PPI despite the higher rate of aspirin use in patients with PPI than in those without PPI. Gastroduodenal ulcer might have been prevented by the PPI in the present study.

PPI have been suggested to cause anemia by several mechanisms. One is suppression of iron absorption. Iron is an essential molecule for cellular physiology, and body iron content is tightly regulated. Because no efficient pathway exists for iron excretion, body iron is regulated primarily at the level of dietary iron absorption. ${ }^{18,19}$ Dietary iron in 2 forms, ferric iron (non-haem) and ferrous iron (haem), is absorbed using distinct transmembrane transport systems consisting of 3 elements: a specific transport protein complex; an enzyme changing the oxidative iron state; and regulatory proteins. Non-haem ferric iron is converted into ferrous iron by reducing enzyme duodenal cytochrome $b$ and absorbed through divalent metal transporter-1 on the cell membrane of the intestinal epithelium. ${ }^{20-24}$ Gastric acid assists in the dissociation of iron salts from food and the reduction of ferric iron to the more soluble ferrous iron. ${ }^{25}$ Krieg et al verified that high $\mathrm{pH}$ in the stomach is associated with iron deficiency anemia, using mice with loss-offunction mutation in the $\alpha$ subunit of $\mathrm{H}^{+}, \mathrm{K}^{+}$-ATPase. ${ }^{26}$ Another mechanism is suppression of vitamin $\mathrm{B}_{12}$ absorption. Gastric acid also facilitates the release of vitamin $B_{12}$ bound to proteins within ingested foodstuffs to permit binding to Rproteins for eventual absorption in the terminal ileum. ${ }^{25}$ Given that PPI are potent gastric acid secretion inhibitors, a decrease in gastric acid secretion due to PPI may affect the absorption of iron and vitamin $B_{12}$, and long-term use of PPI may result in anemia. The frequency of anemia in patients who received histamine $\mathrm{H}_{2}$-blocker tended to be lower than in PPI users and higher than in patients without acid suppression agents, even though these differences did not reach statistical significance. These findings suggest that PPI induces anemia via pH-dependent mechanisms.

With regard to the impact of PPI on iron absorption, how- ever, conflicting results have been reported depending on the disease: for example, PPI had no impact on iron absorption in patients with Zollinger-Ellison syndrome, ${ }^{27}$ whereas they inhibited iron absorption in patients with hemochromatosis. ${ }^{28}$ PPI treatment was associated with anemia but not with low $\mathrm{MCV}$ in the present subjects. These findings suggested that both iron deficiency and vitamin $\mathrm{B}_{12}$ deficiency contributed to the development of anemia.

Given that anemia is directly involved in oxygen transport capacity, it is highly likely to be associated with cardiac function. We have previously reported that anemia was associated with high brain natriuretic peptide concentration in the general population..$^{29}$ Anemia, occurring in as much as $56.7 \%$ of cases of chronic heart failure in Japan, has proven to be an independent risk factor for all-cause mortality, cardiac death, and readmission for exacerbation of heart failure..$^{30}$ Therefore, drug-induced anemia should not be neglected in cardiovascular outpatients, who are often at high risk of heart failure. Accumulation of iron in excess has been implicated in the risk of cardiovascular disease or cancer through increased iron catalyzed free radical-mediated oxidative stress. ${ }^{31,32}$ Moreover, under physiological conditions, a high concentration of $\mathrm{Hb}$ causes stroke and myocardial infarction via thrombus formation. Thus, the effects of long-term PPI on morbidity and mortality in patients with cardiovascular diseases remain to be elucidated. Large-scale prospective studies investigating the prognostic impact of long-term use of PPI in cardiovascular out patients are warranted.

Although Ajmal et al reported that inhibitors of the reninangiotensin system (RAS) such as angiotensin-converting enzyme inhibitor or angiotensin receptor blocker were associated with lower $\mathrm{Hb},{ }^{33} \mathrm{RAS}$ inhibitors were not associated with anemia in the present subjects. The present study may not have had sufficient statistical power to detect effects of RAS inhibitors on $\mathrm{Hb}$ level because of the small sample size. Effects of RAS inhibitors should be examined in a larger subject group in Japan.

\section{Conclusions}

PPI use was associated with decreased $\mathrm{Hb}$ in Japanese cardiovascular outpatients. The long-term impact of PPI-associated anemia in these patients remains to be elucidated.

\section{Study Limitations}

The present study had several limitations. Thorough examination of the gastrointestinal tract was not done in all patients. Latent gastrointestinal bleeding might cause anemia in patients 
with PPI. Second, serum iron, ferritin, and vitamin B12 concentration were not examined. Other unknown mechanisms might contribute to anemia associated with PPI.

\section{Acknowledgments}

We thank students of the Department of Pharmacy, School of Pharmacy, Hyogo University of Health Sciences (Ms Azusa Ueno, Ms Narumi Hara, Ms Yuri Tamura, Mr Takumi Ishida, Ms Shiori Takeuchi, Ms Midori Kitagawa, Ms Yuki Maeda, Mr Yuma Okada, and Ms Sayoko Akinaga) for assisting in the collection of data from medical records.

\section{Disclosures}

No conflicts of interest declared.

\section{References}

1. Ali T, Roberts DN, Tierney WM. Long-term safety concerns with proton pump inhibitors. Am J Med 2009; 122: 896-903.

2. Marcuard SP, Albernaz L, Khazanie PG. Omeprazole therapy causes malabsorption of cyanocobalamin (vitamin B12). Ann Intern Med 1994; 120: 211-215.

3. Lanas A, Bajador E, Serrano P, Fuentes J, Carreno S, Guardia J, et al. Nitrovasodilators, low-dose aspirin, other nonsteroidal antiinflammatory drugs, and the risk of upper gastrointestinal bleeding. $N$ Engl J Med 2000; 343: 834-839.

4. Bhatt DL, Scheiman J, Abraham NS, Antman EM, Chan FK, Furberg $\mathrm{CD}$, et al. ACCF/ACG/AHA 2008 expert consensus document on reducing the gastrointestinal risks of antiplatelet therapy and NSAID use: A report of the American College of Cardiology Foundation Task Force on Clinical Expert Consensus Documents. Circulation 2008; 118: 1894-1909.

5. Komori M, Yasaka M, Kokuba K, Matsuoka H, Fujimoto S, Yoshida $\mathrm{M}$, et al. Intracranial hemorrhage during dabigatran treatment. Circ J 2014; 78: $1335-1341$.

6. Kosiuk J, Koutalas E, Doering M, Nedios S, Sommer P, Rolf S, et al. Comparison of dabigatran and uninterrupted warfarin in patients with atrial fibrillation undergoing cardiac rhythm device implantations. Circ J 2014; 78: 2402-2407.

7. Yasaka M, Lip GY. Impact of non-vitamin $k$ antagonist oral anticoagulants on intracranial bleeding in Asian patients with non-valvular atrial fibrillation. Circ J 2014; 78: 2367-2372.

8. Groenveld HF, Januzzi JL, Damman K, van Wijngaarden J, Hillege HL, van Veldhuisen DJ, et al. Anemia and mortality in heart failure patients: A systematic review and meta-analysis. J Am Coll Cardiol 2008; 52: 818-827.

9. Kaneko H, Suzuki S, Yajima J, Oikawa Y, Sagara K, Otsuka T, et al. Clinical characteristics and long-term clinical outcomes of Japanese heart failure patients with preserved versus reduced left ventricular ejection fraction: A prospective cohort of Shinken Database 20042011. J Cardiol 2013; 62: 102-109.

10. Miura M, Sakata Y, Nochioka K, Takada T, Tadaki S, Ushigome R, et al. Prevalence, predictors and prognosis of patients with heart failure requiring nursing care. Circ J 2014; 78: 2276-2283.

11. Tanaka S, Sakata R, Marui A, Furukawa Y, Kita T, Kimura T. Predicting long-term mortality after first coronary revascularization: The Kyoto model. Circ J 2012; 76: 328-334.

12. Matsuo S, Imai E, Horio M, Yasuda Y, Tomita K, Nitta K, et al. Collaborators developing the Japanese equation for estimated GFR: Revised equations for estimated GFR from serum creatinine in Japan. Am J Kidney Dis 2009; 53: 982-992.

13. Yamada M, Wong FL, Suzuki G. Longitudinal trends of hemoglobin levels in a Japanese population: RERF's Adult Health Study subjects. Eur J Haematol 2003; 70: 129-135.

14. Ng FH, Wong SY, Lam KF, Chang CM, Lau YK, Chu WM, et al.
Gastrointestinal bleeding in patients receiving a combination of aspirin, clopidogrel, and enoxaparin in acute coronary syndrome. Am J Gastroenterol 2008; 103: 865-871.

15. Yano H, Tsukahara K, Morita S, Endo T, Sugano T, Hibi K, et al. Influence of omeprazole and famotidine on the antiplatelet effects of clopidogrel in addition to aspirin in patients with acute coronary syndromes: A prospective, randomized, multicenter study. Circ J 2012; 76: $2673-2680$.

16. Bhatt DL, Cryer BL, Contant CF, Cohen M, Lanas A, Schnitzer TJ, et al. Clopidogrel with or without omeprazole in coronary artery disease. N Engl J Med 2010; 363: 1909-1917.

17. Chitose T, Hokimoto S, Oshima S, Nakao K, Fujimoto K, Miyao Y, et al; on behalf of Kumamoto Intervention Conference Study (KICS) Investigators. Clinical outcomes following coronary stenting in Japanese patients treated with and without proton pump inhibitor. Circ J 2012; 76: 71-78.

18. De Domenico I, McVey Ward D, Kaplan J. Regulation of iron acquisition and storage: Consequences for iron-linked disorders. Nat Rev Mol Cell Biol 2008; 9: 72-81.

19. Andrews NC. Iron metabolism: Iron deficiency and iron overload. Annu Rev Genomics Hum Genet 2000; 1: 75-98.

20. Munoz M, Garcia-Erce JA, Remacha AF. Disorders of iron metabolism. Part 1: Molecular basis of iron homoeostasis. J Clin Pathol 2011; 64: 281-286.

21. Zhang AS, Enns CA. Molecular mechanisms of normal iron homeostasis. Hematology Am Soc Hematol Educ Program 2009; 1: 207214.

22. Hentze MW, Muckenthaler MU, Galy B, Camaschella C. Two to tango: Regulation of mammalian iron metabolism. Cell 2010; 142: $24-38$.

23. Anderson GJ, Frazer DM, McLaren GD. Iron absorption and metabolism. Curr Opin Gastroenterol 2009; 25: 129-135.

24. Anderson GJ, Vulpe CD. Mammalian iron transport. Cell Mol Life Sci 2009; 66: 3241-3261.

25. McColl KE. Effect of proton pump inhibitors on vitamins and iron. Am J Gastroenterol 2009; 104(Suppl 2): S5-S9.

26. Krieg L, Milstein O, Krebs P, Xia Y, Beutler B, Du X. Mutation of the gastric hydrogen-potassium ATPase alpha subunit causes irondeficiency anemia in mice. Blood 2011; 118: 6418-6425.

27. Stewart CA, Termanini B, Sutliff VE, Serrano J, Yu F, Gibril F, et al. Iron absorption in patients with Zollinger-Ellison syndrome treated with long-term gastric acid antisecretory therapy. Aliment Pharmacol Ther 1998; 12: 83-98.

28. Hutchinson C, Geissler CA, Powell JJ, Bomford A. Proton pump inhibitors suppress absorption of dietary non-haem iron in hereditary haemochromatosis. Gut 2007; 56: 1291-1295.

29. Matsumoto M, Tsujino T, Naito Y, Lee-Kawabata M, Ezumi A, Yamamoto K, et al. Anemia as a factor that elevates plasma brain natriuretic peptide concentration in apparently healthy subjects. Int Heart J 2008; 49: 577-586.

30. Hamaguchi S, Tsuchihashi-Makaya M, Kinugawa S, Yokota T, Takeshita A, Yokoshiki H, et al. Anemia is an independent predictor of long-term adverse outcomes in patients hospitalized with heart failure in Japan: A Report from the Japanese Cardiac Registry of Heart Failure in Cardiology (JCARE-CARD). Circ J 2009; 73: $1901-1908$.

31. Sullivan JL. Iron and the sex difference in heart disease risk. Lancet 1981; 1: 1293-1294.

32. Zacharski LR, Chow BK, Howes PS, Shamayeva G, Baron JA, Dalman RL, et al. Decreased cancer risk after iron reduction in patients with peripheral arterial disease: Results from a randomized trial. J Natl Cancer Inst 2008; 100: 996-1002.

33. Ajmal A, Gessert CE, Johnson BP, Renier CM, Palcher JA. Effect of angiotensin converting enzyme inhibitors and angiotensin receptor blockers on hemoglobin levels. BMC Res Notes 2013; 6: 443. 